\title{
'Black Diamond' Thornless Trailing Blackberry
}

Chad E. Finn

\author{
U.S. Department of Agriculture, Agricultural Research Service, Horticultural \\ Crops Research Laboratory, Northwest Center for Small Fruit Research, \\ Corvallis, OR 97330
}

Brian M. Yorgey

Department of Food Science, Oregon State University, Corvallis, OR 97331

Bernadine C. Strik

Department of Horticulture, Oregon State University, Corvallis, OR 97331

Harvey K. Hall

New Zealand HortResearch Inc., Nelson Region, Old Mill Road, P.O. Box 220, Motueka, New Zealand

\section{Robert R. Martin}

U.S. Department of Agriculture, Agricultural Research Service, Horticultural Crops Research Laboratory, Northwest Center for Small Fruit Research, Corvallis, OR 97330

\section{Michael Qian \\ Department of Food Science, Oregon State University, Corvallis, OR 97331}

Additional index words. Rubus, fruit breeding, spineless

'Marion' is currently the most important blackberry (Rubus L. subgenus Rubus) cultivar in the world as it is the predominant cultivar grown for the processed-fruit market (Finn et al., 1997). While 'Marion' produces fruit of outstanding quality for processing, the plants are thorny (botanically termed spiny). When 'Marion' is machine harvested, thorns can end up in the product(Strik andBuller, 2002), which can lead to a poor product, and, more significantly, in an economic sense, lawsuits. As a result, a primary priority for the breeding program has been the development of cultivars that are thornless, machine harvestable, and retain the excellent processing characteristics of 'Marion'. Three thornless blackberry cultivars with these qualities are being released simultaneously: 'Black Diamond', 'Black Pearl' (Finn et al., 2005a), and 'Nightfall' (Finn et al., 2005b).

'Black Diamond' is a thornless trailing blackberry from the U.S. Department of AgricultureAgricultural Research Service (USDA-ARS) breeding program in Corvallis, Ore., released in cooperation with the Oregon State University Agricultural Experiment Station and the Washington State University Agricultural Research Center (Fig. 1). 'Black Diamond' is high-yield-

Received for publication 8 June 2005. Accepted for publication 18 Aug. 2005. This research was partially funded by the Oregon Raspberry and Blackberry Commission and the Northwest Center for Small Fruit Research. We gratefully acknowledge the assistance of Mary Peterson, Connie Pace, and Gloria Murray in 'Black Diamond's evaluation; Nola Mosier in freeing the nuclear stock of known viruses; Derek Peacock, formerly of Enfield Farms (Lynden, Wash.), and Gary Moulton (WSU-Mount Vernon) for trial results. ing, vigorous, adapted to machine harvesting, and produces a very good processed product. In addition, the fruit are firm enough and the drupelet epidermis tough enough to be suited to some fresh market applications.

\section{Origin}

In 1997, 'Black Diamond' was selected in Corvallis from a 1991 cross of 'Kotata' $\times$ NZ 8610L-163 (E90 $\times$ N-71) made by H. Hall of New Zealand HortResearch Inc. in NewZealand and tested as NZ 9128R-1 (Fig. 1). 'Kotata' is a heptaploid $(2 \mathrm{n}=7 \mathrm{x}=49)$ commercial trailing cultivar of complex eastern and western blackberry parentage (Lawrence, 1984; Thompson, 1995). E90 was selected from an open pollinated population of a USDA-Oregon State University (OSU) selection OSC 2005, which is a complex hybrid whose spinelessness is derived through NC 37-35-M-2 from 'Austin Thornless'. OSC 2005 also has the western U.S. developed trailing cultivars 'Marion', 'Olallie', and 'Logan', along with the eastern blackberry 'Eldorado', which is a chance seedling from Ohio, in its pedigree.
$\mathrm{N}-71$ 's parentage is much more straightforward but nonetheless complex as it is a cross between 'Aurora', a trailing cultivar whose ploidy is $8 \mathrm{x}$ +2 , and 'Comanche' a $4 x$ erect blackberry from the University of Arkansas. 'Black Diamond' is the result of tremendous cooperation amongst breeders who have shared their germplasm.

\section{Description and Performance}

While 'Black Diamond' has been tested on grower sites and research stations in Oregon and Washington, the most thorough testing was done at the Oregon State University North Willamette Research and Extension Center (NWREC) in Aurora. In each of the trial plantings, standard cultural practices for trailing blackberry production were used, including annual pre- and postemergent herbicide applications, annual spring nitrogen fertilization ( $78 \mathrm{~kg} \mathrm{~N} / \mathrm{ha}$ ), postharvestremoval of floricanes, training of primocanes to a two wire trellis, and weekly overhead application of about $2.5 \mathrm{~cm}$ of irrigation. All plantings received applications of dormant season fungicides (liquid lime sulfur and copper hydroxide) to control leaf and cane spot (Septoria rubi Westend.), purple blotch [Septocyta ruborum (Lib.) Petr.], rust [Kuehneola uredinis (Link)Arth.], and anthracnose [Elsinoe veneta (Burkholder) Jenk.]. They also received a single bloom application of captan to control anthracnose, botrytis (Botrytis cinerea Pers.: Fr.), cane spot, purple blotch, and stamen blight [Hapalosphaeria deformans (Syd.) Syd.] at labeled rates. The replicated planting at NWREC was arranged in a randomized complete block design, with four, three-plant replications used for fresh fruit characteristics and three replications hand harvested once per week to determine, harvest season, yield, and fruit weight. The average fruit weight for a season is a weighted mean based on the weight of a randomly selected subsample of 25 fruit from each harvest. These data, collected from 2001-03, were analyzed as a split plot in time with cultivar as the main plot and year as the subplot. Of the 23 genotypes harvested in replicated trial for yield, only the data from 'Marion', 'Silvan', 'Siskiyou', and 'Waldo' and the new releases 'Black Diamond', 'Black Pearl' (Finn et al., 2005a), and 'Nightfall' (Finn et al, 2005b) were included in the analysis (PROC GLM; SAS Institute, Cary, N.C.). The cultivar $\times$ year interaction was significant for yield but not for fruit weight. Therefore, the interaction means for yield are presented and compared using Duncan's multiple range test (Table

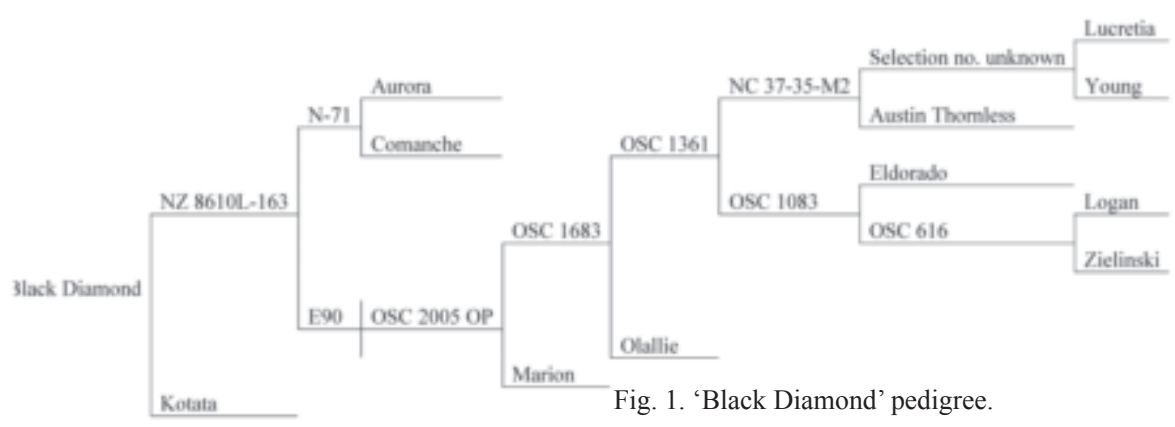


Table 1. Fruit weight and yield in 2001-03 for blackberry genotypes planted in 1999 in replicated trial at the Oregon State University-North Willamette Research and Extension Center in Aurora.

\begin{tabular}{|c|c|c|c|c|c|}
\hline \multirow[b]{3}{*}{ Genotype } & \multirow{2}{*}{$\begin{array}{c}\text { Fruit } \\
\text { size }(g)^{z}\end{array}$} & \multicolumn{4}{|c|}{ Yield $\left(\mathrm{kg} \cdot \mathrm{ha}^{-1}\right)$} \\
\hline & & & & & Mean \\
\hline & $\overline{2001-03}$ & 2001 & 2002 & 2003 & $2001-03$ \\
\hline Nightfall & $6.2 \mathrm{~b}$ & $42447 \mathrm{a}$ & $13405 \mathrm{a}$ & $20962 \mathrm{a}$ & $25604 \mathrm{a}$ \\
\hline Silvan & $6.2 \mathrm{bc}$ & $31757 \mathrm{ab}$ & $16811 \mathrm{a}$ & $21485 \mathrm{a}$ & 23351 a \\
\hline Black Diamond & $5.8 \mathrm{~cd}$ & $29281 \mathrm{a}-\mathrm{c}$ & $15568 \mathrm{a}$ & $19001 \mathrm{a}$ & $21283 \mathrm{ab}$ \\
\hline Marion & $5.1 \mathrm{e}$ & $26380 \mathrm{a}-\mathrm{c}$ & $13021 \mathrm{a}$ & 18397 a & $19266 \mathrm{ab}$ \\
\hline Black Pearl & $6.2 \mathrm{~b}$ & $26969 \mathrm{a}-\mathrm{c}$ & $14373 \mathrm{a}$ & $15505 \mathrm{ab}$ & $18949 a b$ \\
\hline Waldo & $5.5 \mathrm{~d}$ & $25849 \mathrm{bc}$ & $11000 \mathrm{a}$ & $17286 \mathrm{a}$ & $18045 \mathrm{ab}$ \\
\hline Siskiyou & $6.9 \mathrm{a}$ & 20969 c & $9854 \mathrm{a}$ & $9359 \mathrm{~b}$ & $13394 \mathrm{~b}$ \\
\hline
\end{tabular}

${ }^{2}$ Means withing a column followed by the same letter are not significantly different $p>0.05$, by Duncan's multiple range test.

Table 2. Mean ripening season and date at which yield of each genotype reached the given percentage of total yield at the Oregon State University-North Willamette Research and Extension Center in Aurora. Trial was planted in 1999 and harvested in 2001-03.

\begin{tabular}{lccc}
\hline & \multicolumn{3}{c}{ Harvest season } \\
\cline { 2 - 4 } Genotype & $5 \%$ & $50 \%$ & $95 \%$ \\
\hline Metolius & 25 June & 3 July & 14 July \\
Obsidian & 25 June & 4 July & 15 July \\
Silvan & 26 June & 8 July & 21 July \\
Black Diamond & 28 June & 8 July & 21 July \\
Siskiyou & 25 June & 8 July & 25 July \\
Black Pearl & 3 July & 10 July & 24 July \\
Marion & 3 July & 10 July & 22 July \\
Nightfall & 3 July & 11 July & 23 July \\
Waldo & 8 July & 22 July & 7 Aug. \\
\hline
\end{tabular}

Table 3. Yield and harvest season for blackberry genotypes planted in one or two five-plant plots (1.4-m plant spacing) in 2001 and 2002 at Enfield Farms in Lynden, Wash. Plants were harvested primarily with an over-the-row harvester (Littau, Stayton, Ore.) with a horizontal (Christy) head.

\begin{tabular}{|c|c|c|c|c|c|}
\hline \multirow[b]{2}{*}{ Genotype } & \multirow{2}{*}{$\begin{array}{c}\text { Yield } \\
\left(\mathrm{kg}^{2} \mathrm{ha}^{-1}\right)\end{array}$} & \multicolumn{3}{|c|}{2003 Harvest season } & \multirow{2}{*}{$\begin{array}{l}\text { No. } \\
\text { plots }\end{array}$} \\
\hline & & $5 \%$ & $50 \%$ & $95 \%$ & \\
\hline Black Diamond & 17281 & 11 July & 21 July & 6 Aug. & 2 \\
\hline Nightfall & 14384 & 11 July & 25 July & 6 Aug. & 1 \\
\hline Silvan & 12106 & 11 July & 21 July & 3 Aug. & 2 \\
\hline Marion & 10382 & 11 July & 21 July & 6 Aug. & 2 \\
\hline Siskiyou & 9656 & 11 July & 21 July & 31 July & 1 \\
\hline Boysen & 8670 & 16 July & 25 July & 31 July & 1 \\
\hline Metolius & 8480 & 11 July & 11 July & 25 July & 1 \\
\hline Waldo & 7112 & 21 July & 31 July & 6 Aug. & 2 \\
\hline
\end{tabular}

1). The fruit ripening season in Oregon was characterized by the dates at which $5 \%, 50 \%$, and $95 \%$ of the total fruit yield were harvested. (Table 2). In 2003, fruit were harvested by an over-the-row harvester (Littau, Stayton, Ore.) with a horizontal (Christy) head from one or two, five-plant plots planted in 2001 at Enfield Farms (Lynden, Wash.). Yield and harvest season were determined for 38 genotypes, 7 of which are presented in this report (Table 3 ). Subjective fruit evaluations were made during the fruiting season using a 1 to 9 scale by tasting berries in the field) (Table 4). Plant ratings were conducted one time each year from 2001-03 during the fruiting season for primocane and floricane vigor, spines $(9=$ spineless; cultivars derived from 'Austin Thornless' are seldom completely spineless, basal spines are common, and occasionally a single spine on the lower side of the petiolule), and flowering or fruiting lateral length $(1=$ very short, $5=$ very long) and strength ( 1 = weak, droopy; 5 = stiff, sturdy) (Table 4). In separate studies, the chemical characteristics of commercial blackberry cultivars and advanced selections including 'Black Diamond' were evaluated (Moyer et al., 2002; Siriwoharn et al., 2004). Yorgey and Finn (2005) prepared individually quick frozen and puree products from several genotypes for evaluation by a blind panel of untrained experts.

In Oregon, 'Black Diamond' had a similar yield to 'Silvan', 'Marion', and 'Waldo' but a greater yield than 'Siskiyou' in each year except 2002 (Table 1). In the Washington State trial, 'Black Diamond' had the highest machineharvest yield (Table 3). 'Black Diamond' fruit are medium sized, consistently larger than 'Marion', but smaller than 'Siskiyou' (Table 1).

'Black Diamond' harvest begins in late June, peaks in early July and is largely done by the third week of July in Oregon (Table 2). The harvest season begins 4 to $5 \mathrm{~d}$ ahead of 'Marion' but peaks about 2 d ahead of 'Marion'. 'Black Diamond' is definitely later ripening than 'Obsidian' and 'Metolius' and much earlier than 'Waldo'. In Washington, in 2003, 'Black Diamond's harvest season was identical to 'Marion' for machine harvested fruit.

Fruit of 'Black Diamond' are uniform, conical, and attractive (Table 4, Fig. 2). They are similar to 'Waldo' in uniformity of shape and much less uneven than 'Marion'. For a trailing blackberry, 'Black Diamond' has excellent firmness, much better than 'Marion' or 'Silvan' and comparable to commercially shipped fresh-market cultivars 'Kotata' and 'Chester Thornless' (Table 3). This firmness leads to a high quality machine-harvested product and provides the opportunity for a good fresh market product if hand harvested. 'Black Diamond' fruit are similar in color to those of 'Marion' and are much less purple or more black than 'Silvan' (Table 4). The fruit separate from the plant easily by hand (Table 4) or by machine (Table 3). As a fresh fruit,

Table 4. Mean scores for subjectively evaluated characteristics ${ }^{\mathrm{z}}$ of 'Black Diamond' and eight commercial blackberry cultivars planted in 1999 at the Oregon State University-North Willamette Research and Extension Center in Aurora.

\begin{tabular}{|c|c|c|c|c|c|c|c|c|c|c|c|}
\hline \multirow[b]{2}{*}{ Cultivar } & \multirow{2}{*}{$\begin{array}{c}\text { Primocane } \\
\text { vigor }\end{array}$} & \multirow[b]{2}{*}{ Thorns } & \multirow{2}{*}{$\begin{array}{c}\text { Floricane } \\
\text { vigor }\end{array}$} & \multicolumn{2}{|c|}{ Fruiting lateral } & \multicolumn{6}{|c|}{ Fruit } \\
\hline & & & & Length & Strength & Firm & Color & Shape & Texture & Separation & Flavor \\
\hline Black Diamond & 8.3 & 8.6 & 8.4 & 3.0 & 3.7 & 7.3 & 8.3 & 8.9 & 8.2 & 8.5 & 6.8 \\
\hline Chester Thornless & 9.0 & 9.0 & 8.7 & 4.8 & 3.4 & 7.2 & 8.7 & 6.2 & 5.5 & 8.4 & 6.2 \\
\hline Kotata & 9.0 & 3.3 & 8.6 & 3.2 & 3.9 & 7.4 & 8.9 & 7.7 & 8.4 & 8.8 & 7.7 \\
\hline Marion & 9.0 & 4.6 & 8.5 & 4.8 & 3.3 & 5.4 & 8.3 & 6.7 & 8.9 & 8.9 & 8.6 \\
\hline Metolius & 9.0 & 2.5 & 7.9 & 4.3 & 4.7 & 8.2 & 8.7 & 8.8 & 8.8 & 8.8 & 7.8 \\
\hline Obsidian & 8.9 & 4.9 & 8.8 & 3.5 & 3.3 & 7.7 & 8.6 & 7.5 & 8.0 & 8.2 & 7.5 \\
\hline Silvan & 9.0 & 3.1 & 7.9 & 3.5 & 2.7 & 3.9 & 7.1 & 7.2 & 8.2 & 8.6 & 8.0 \\
\hline Siskiyou & 9.0 & 4.0 & 8.5 & 4.1 & 3.6 & 8.1 & 8.7 & 8.1 & 8.5 & 8.9 & 8.2 \\
\hline Waldo & 8.6 & 8.4 & 7.6 & 1.7 & 4.5 & 7.0 & 8.6 & 8.9 & 8.8 & 8.8 & 6.9 \\
\hline
\end{tabular}

${ }^{2}$ Characteristics (except for laterals) scored on a 1 to 9 scale, where $1=$ the poorest expression of the trait and $9=$ the best expression of the trait, i.e., $9=$ very vigorous, spineless, very firm, black, uniform shape, pleasant to chew not seedy, separates easily from the plant, and intense flavor, respectively. Lateral characteristics scored on a 1 to 5 scale, where $1=$ short or weak laterals and $5=$ long or strong laterals. 
'Black Diamond' has good flavor, though not as intense or aromatic as that of 'Marion' (Table 4).

Siriwoharn et al. (2004) and Moyer et al. (2002) evaluated 'Obsidian' along with a number of other genotypes for among other things total soluble solids, titratable acidity, total phenolics, total anthocyanins, polyphenolic content, oxygen radical absorbance capacity (ORAC), and ferric reducing antioxidant power (FRAP). While Moyer et al. (2002) generally reported lower values for total phenolics, total anthocyanins, ORAC and FRAP than did Siriwoharn et al. (2004), the genotypes in common were ranked similarly. The primary purpose of Moyer et al. (2002) was to look at a great diversity of germplasm and therefore sampling was limited whereas, Siriwoharn et al. (2004) evaluated a much smaller number of genotypes in multiple years with greater sampling and will therefore be the focus of discussion here. 'Black Diamond' fruit had similar total soluble solids to 'Marion', 'Silvan', and 'Waldo', but total soluble solids were greater than those of 'Chester Thornless'. The total titratable acidity for 'Black Diamond' was less than 'Waldo', similar to 'Marion' and 'Silvan', and greater than 'Chester Thornless' and 'Thornless Evergreen'. Total phenolics, total anthocyanins, ORAC values, and FRAP values for 'Black Diamond' fruit were less than those for 'Marion', but similar to 'Silvan'. While the proportion of polyphenolics varied greatly among genotypes in their study, 'Black Diamond' had below average amounts of procyanidins, ellagitannins, flavonols, and ellagic acid when compared to the other 10 genotypes examined. In comparison to 'Marion', 'Black Diamond' had greater levels of procyanidins, lower levels of ellagitannins, and, similar levels of flavonols and ellagic acid.

'Black Diamond' and other new cultivars were evaluated by a blind panel as individually quick frozen (IQF) and puree samples (Yorgey and Finn, 2005). As an IQF fruit, 'Black Diamond' was ranked similarly to 'Marion' and 'Waldo' in perceived color and appearance; and similar to 'Waldo', but ranked lower than 'Marion', for flavor, seediness and overall quality. As a puree, 'Black Diamond', was ranked similarly to 'Waldo', 'Marion', and 'Silvan' for aroma, flavor, color, and overall quality. The combination of input from these panels and other informal evaluations suggest that 'Black Diamond' will process well, but does not have the intense flavor of 'Marion'.

'Black Diamond' plants are less vigorous than those of 'Marion' and 'Silvan' (Table 4); this is seen as a positive trait by the commercial industry because 'Marion' and 'Silvan' can produce an extremely large amount of vegetative growth that must be managed. One commercial grower spaced plants at $0.91 \mathrm{~m}$ within the row instead of the more typical 1.8 $\mathrm{m}$ and was happy with the results (C. Ford, Sakuma Brothers Farms, Burlington, Wash., personal communication). 'Black Diamond' is thornless by commercial standards, however the primocanes are thorny on the basal 30 to $40 \mathrm{~cm}$, a height below the catcher plates on a harvest machine. 'Black Diamond' has fruiting laterals that are medium in length and tend to be stiffer than those of 'Marion' and 'Silvan'. Plants of 'Black Diamond', pruned to a similar number of canes as 'Marion' and 'Kotata', have a more open, less dense plant habit and the fruiting laterals are shorter and sturdier than those of 'Marion'. This growth habit makes it well suited for machine harvest.

In our trials, under a minimal spray program, 'Black Diamond' has been free of serious cane, leaf or fruit diseases. 'Black Diamond' is not particularly susceptible to Septoria leaf spot and purple blotch. 'Black Diamond' does not exhibit vegetative or fruit symptoms of cane and leaf rust. In some years, particularly 1997 , 'Marion', 'Kotata', and 'Black Butte' were severely damaged by a dryberry syndrome. The cause of this problem is not known currently but is suspected to be a complex of diseases, particularly anthracnose, that develops under certain combinations of temperature and moisture. 'Black Diamond' has occasionally shown symptoms of dryberry in our trials, however it has never been noted in grower fields where the plants are treated more extensively with fungicides.

No significant winter injury has been noted on this genotype since it was selected in 1997 , however, the winters, even where it has been grown in northern Washington, have been mild. In Fall 2003, the temperatures dropped rapidly to -3 to $-6{ }^{\circ} \mathrm{C}$ in Oregon and -4 to $-8{ }^{\circ} \mathrm{C}$ in northern Washington during the last two days of October. Many genotypes including 'Marion' and 'Silvan', but not 'Black Diamond', were severely damaged (cane and bud death) by this rapid change in temperature in our Washington, but not our Oregon, trials. One reason for the greater damage in Washington may be that the plots were in a commercial red raspberry field where plants were heavily fertilized with nitrogen and irrigated to maximize growth the first year and yield the following year. This approach may have led to injury on plants that were not yet dormant. Nonetheless, 'Black Diamond' came through this episode with much less damage than 'Marion'.

'Black Diamond' caught the attention of several growers from the time it was first selected. As a result, it has been planted in small plots at commercial grower's fields in Oregon's Willamette Valley and Washington's Skagit Valley as well as at Washington State University-Mount Vernon. In each of these locations, 'Black Diamond' has performed well.

Outstanding characteristics of 'Black Dia-
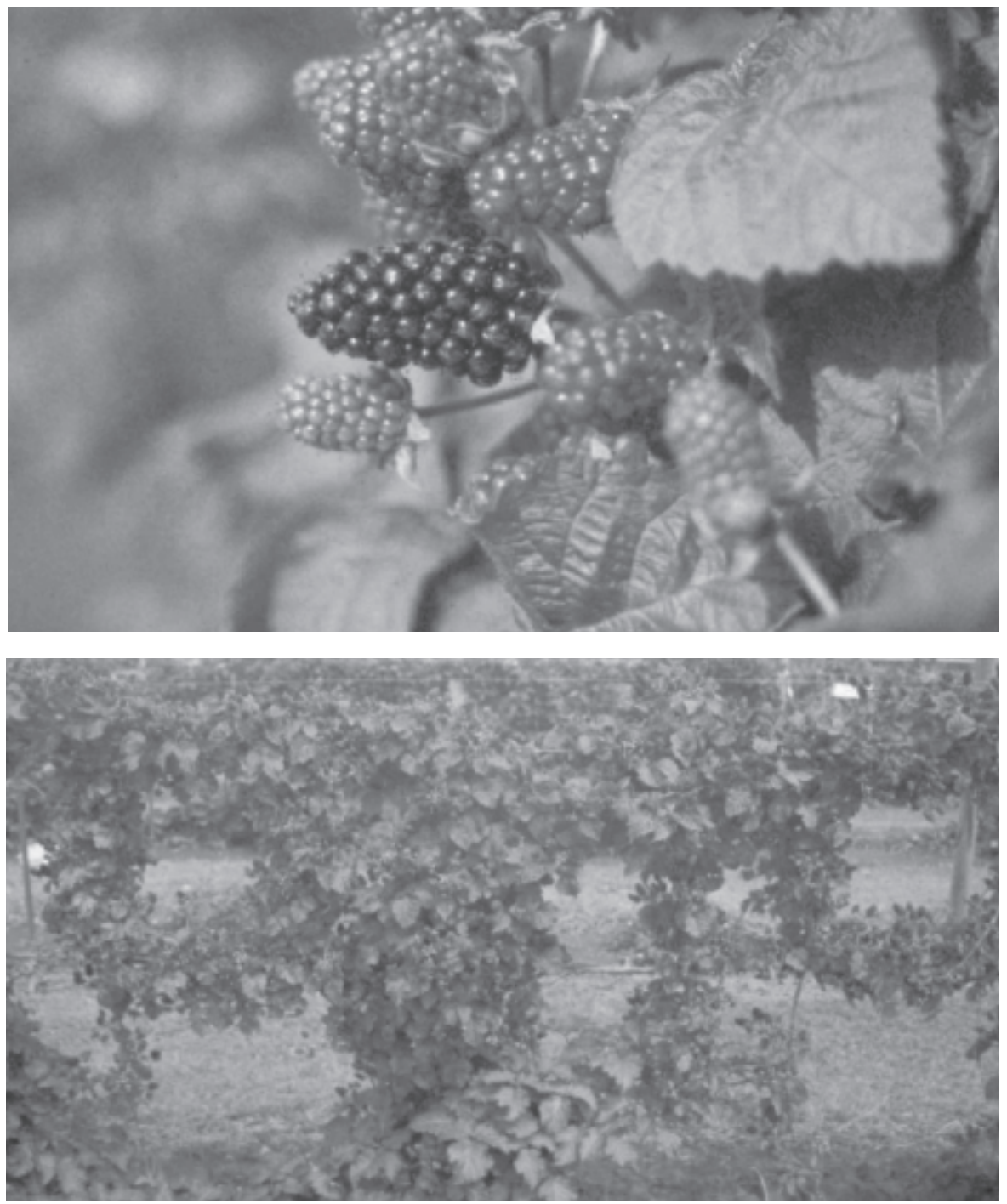

Fig. 2. 'Black Diamond' (top) fruit and (bottom) plant. 
mond' include large, uniformly shaped and firm fruit, a yield similar to that of 'Marion', good processed fruit quality, excellent adaptation to machine harvesting, and thornless plants with good disease tolerance. 'Black Diamond' will be a popular commercial cultivar for the processed blackberry industry. 'Black Diamond' will also be suited for local fresh market sales and for homeowners. 'Black Diamond' is expected to perform well in areas where trailing blackberries are adapted, including the Pacific Northwest, California, Chile, New Zealand, United Kingdom, and the Mediterranean region.

\section{Availability}

'Black Diamond' is not patented. When this germplasm contributes to the development of a new cultivar or germplasm, the authors request that appropriate recognition be given to the source. 'Black Diamond' nuclear stock has tested negative for tomato ringspot, raspberry bushy dwarf, and tobacco streak viruses by ELISA and has indexed negative on grafting to $R$. occidentalis. Further information or a list of nurseries propagating 'Black Diamond' is available on written request to the contact author. The USDA-ARS does not have commercial quantities of plants to distribute. In addition, plants of 'Black Diamond' have been deposited in the National Plant Germplasm System, atUSDA-ARS NCGR in Corvallis, accession number PI 638257, where it is available for research purposes, including development and commercialization of new cultivars.

\section{Literature Cited}

Finn, C.E., B.M. Yorgey, B.C. Strik, R.R. Martin, and M.C. Qian. 2005b. 'Black Pearl'thornless trailing blackberry. HortScience 40:2179-2181.

Finn, C.E., B.M. Yorgey, B.C. Strik, R.R. Martin, and M.C. Qian. 2005a. 'Nightfall' thornless trailing blackberry. HortScience 40:2182-2184.
Finn, C., B.C. Strik, and F.J. Lawrence. 1997. Marion trailing blackberry. Fruit Var. J. 51: 130-132.

Lawrence, F.J. 1984. Naming and release of blackberry cultivar Kotata. U.S. Dept. Agr. Release Notice.

Moyer, R.A., K.E. Hummer, C.E. Finn, B. Frei, and R.E. Wrolstad. 2002. Anthocyanins, phenolics and antioxidant capacity in diverse small fruits: Vaccinium, Rubus, and Ribes. J.Agr. Food Chem. 50:519-525.

Siriwoharn, T, R.E. Wrolstad, C.E. Finn, and C.B. Pereira. 2004. Influence of cultivar, maturity and sampling on blackberry (Rubus L. hybrids) anthocyanins, polyphenolics, and antioxidant properties. J. Agr. Food Chem. 52:8021-8030.

Strik, B. and G. Buller. 2002. Reducing thorn contamination in machine-harvested 'Marion' blackberry. Acta Hort. 585:677-681.

Thompson, M.M. 1995. Chromosome numbers of Rubus cultivars at the National Clonal Germplasm Repository. HortScience 30:1447-1452.

Yorgey, B.M. and C.E. Finn. 2005. Comparison of 'Marion' to thornless blackberry genotypes as individually quick frozen and puree products. HortScience 40:513-515. 